\title{
A New Method for Strengthening Gold
}

\author{
Alan Russell, Kai Xu, Scott Chumbley, James Parks and Joel Harringa \\ Ames Laboratory of Iowa State University, Ames, IA 50011, USA
}

\begin{abstract}
Metal-metal composites were first produced in a copper matrix in the 1970's, and they have since been produced in several other binary metal systems. This strengthening technique reinforces a ductile metal matrix with a ductile metal second phase. In some binary systems, this technique confers extraordinarily high strength and hardness while still maintaining low electrical resistivity. This article reports on the first gold matrix metal-metal composite, which was produced by deformation processing a $90 \% \mathrm{Au}-10 \% \mathrm{Ag}$ powder compact. The Au-Ag specimen studied had an ultimate tensile strength of $550 \mathrm{MPa}$ and an electrical resistivity only $8 \%$ higher than that of pure Au at a deformation processing true strain of 5.6 . The $590 \mathrm{~nm}$ average $\mathrm{Ag}$ filament thickness in this composite was relatively coarse compared to other deformation processed composites, which suggests that substantially higher strengths would be possible in a gold matrix metal-metal composite using deformation processing to higher true strains to reduce the filament thickness.
\end{abstract}

\section{DEFORMATION PROCESSED METAL-METAL COMPOSITES}

During the past two decades, a new class of copperrefractory metal composites has been developed with extraordinary mechanical and electrical properties (13). These composites, composed of face-centered cubic Cu with 10 to $30 \%$ by volume element $\mathrm{X}$ (where $\mathrm{X}$ is a body-centered cubic metal immiscible in $\mathrm{Cu}$, such as $\mathrm{Nb}, \mathrm{V}, \mathrm{Ta}, \mathrm{Cr}$, or $\mathrm{Fe}$ ), are severely deformed by extrusion/swaging/wire drawing or by rolling to produce the nanometer-scale microstructure of $\mathrm{X}$ filaments in a $\mathrm{Cu}$ matrix shown in Figure 1. The $\mathrm{Cu}^{-}$ $20 \% \mathrm{Nb}$ system is the most thoroughly studied of these composites. These materials are best known for their extraordinary tensile strengths, which can be as high as $2400 \mathrm{MPa}$ after deformation to a true strain $(\eta)$ of 12 (4). However, they possess other unusual properties as well, including:

- strength-to-electrical-resistivity ratios much higher than those of any copper alloy

- the smallest filamentary microstructures (phase size) of any material available in bulk quantities

- phase structures with very low dislocation densities, approaching whisker quality in many cases

The $\mathrm{Cu}-\mathrm{X}$ deformation-processed metal metal composites (DMM $\mathrm{D} C$ 's) are characterized by remarkable ductility, which allows cast- or powder-processed starting billets to be deformed as much as $\eta=13.4$ (5). Such deformations represent more than an 800-fold reduction in diameter and are accompanied by a concomitant reduction in the thickness and spacing of the $\mathrm{X}$ phase. Thus, an as-cast billet of $\mathrm{Cu}-20 \mathrm{Nb}$, displaying $\mathrm{Nb}$ dendrites with an average thickness of

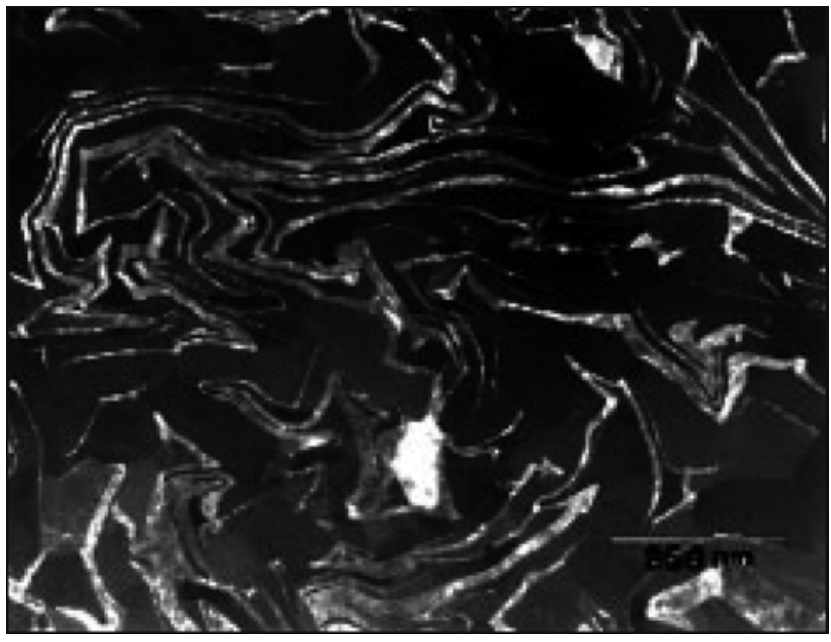

Figure 1 TEM micrograph of a $\mathrm{Cu}$-20Nb DMMC at a true strain of 9 sectioned transversely and photographed in conical scan dynamic dark field conditions to show the $\mathrm{Nb}$ filaments as the light grey phase and the $\mathrm{Cu}$ matrix as the dark grey phase. Note that the $\mathrm{Nb}$ filaments are typically 10 to $25 \mathrm{~nm}$ thick; their original thickness in the cast starting ingot $(\eta=0)$ was 5 to $12 \mu \mathrm{m}$. 


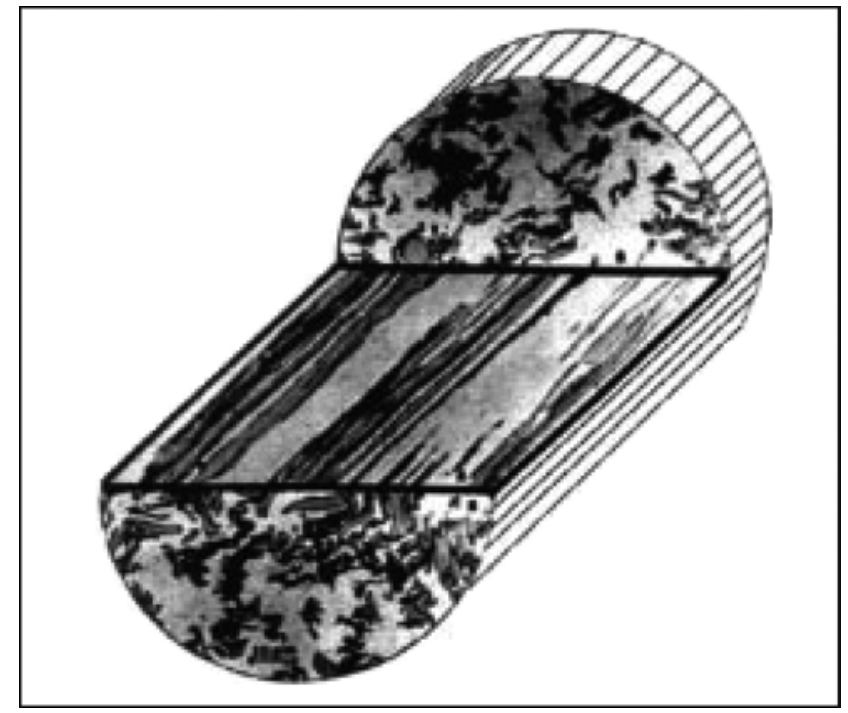

Figure 2 Combined SEM photographs of transverse and longitudinal section views of a $\mathrm{Cu}-20 \% \mathrm{Nb} D M M C$ $(\eta=3.6)$ arranged to depict its microstructural phase shape in relation to the wire specimen's overall dimensions. Note the convoluted ribbon shape of the $b c c N b$ filaments caused by the plane strain of the $b c c$ [110] fiber axis deformation texture. Fcc filaments would remain approximately cylindrical in shape.

$5 \mu \mathrm{m}$, may be deformation processed at room temperature into a wire with $\mathrm{Nb}$ filaments averaging $7 \mathrm{~nm}$ thick (6). These in situ processed composites have strengths substantially greater than the strengths of any other $\mathrm{Cu}$ alloys. Debate continues on the mechanism(s) that account for the high strengths of the $\mathrm{Cu}-\mathrm{X}$ composites (7-11), but discussion centers around the role of the nanofilamentary $\mathrm{X}$ structure in impeding propagation and motion of dislocations in both the $\mathrm{Cu}$ and $\mathrm{X}$ phases.

In an effort to extend these desirable deformation processing attributes to non-copper systems, the authors have produced several DMMC's with hexagonal close-packed ( $\mathrm{Ti}, \mathrm{Y}, \mathrm{Sc}$, and $\mathrm{Mg}$ ), bodycentered cubic $(\mathrm{Nb}, \mathrm{Fe}, \mathrm{V}, \mathrm{Mo}, \beta-\mathrm{Ti})$, and facecentered cubic (Al, $\mathrm{Au}$, and $\mathrm{Ni}$ ) metals. This work began in 1990, and continues today (12-14). Two major conclusions can be drawn from these experiments:

1. A large number of ductile metals can produce nano-scale DMMC's, and

2. Hexagonal close-packed (hcp) and body-centered cubic (bcc) metals develop textures during axisymmetric deformation processing that cause plane strain in the developing filaments, forming convoluted ribbon-shaped filaments (see Figures
1-2). In contrast, face-centered cubic (fcc) metals with their larger number of slip systems do not deform in plane strain and are capable of forming filaments that are more nearly cylindrical in shape.

\section{GOLD MATRIX DEFORMATION PROCESSED METAL-METAL COMPOSITES (DMMC'S)}

The fcc structure of gold and the numerous applications for gold requiring hardness, high strength, and high electrical conductivity suggest that gold would be an excellent candidate matrix for a DMMC. However, equilibrium gold binary systems with other ductile metals are not ideally suited for DMMC formation, since few gold binary systems possess the desired criteria of low mutual solid solubility and the absence of intermetallic compounds. Two systems that do meet these criteria are $\mathrm{Au}-\mathrm{Rh}$ and $\mathrm{Au-Mo}$, and the authors first attempted to make a gold DMMC with meltprocessed $\mathrm{Au}-\mathrm{Rh}$ and Au-Mo specimens. However, in both systems the flow stress of the second phase metal is much higher than that of the gold matrix, and the second phase metals failed to plastically deform.

In binary systems where equilibrium phase diagrams are poorly suited to melt processing, an alternate method to prepare a DMMC is powder processing of the two metal powders. In such powder processed DMMC's, a microstructure consisting of the two elemental phases can be preserved by performing all processing steps at temperatures low enough to prevent formation of equilibrium microstructures. P/M may prove to be the only feasible means of producing Au matrix DMMC's, and this method was used to produce the Au-Ag DMMC described in the remainder of this paper.

\section{Experimental Procedure}

Au powder of $99.95 \%$ metals basis purity and 1.6 to $6.8 \mu \mathrm{m}$ particle size was mixed with $\mathrm{Ag}$ powder (99.9\% metals basis purity) of 4 to $7 \mu \mathrm{m}$ particle size. These powders were blended and cold isostatically pressed at $138 \mathrm{MPa}$ to form a 29.4 -gram green compact of $90 \mathrm{vol} \% \mathrm{Au}$ and $10 \mathrm{vol} \% \mathrm{Ag}$. The $11.1 \mathrm{~mm}$ diameter CIP'ed compact was sealed into a $\mathrm{Cu}$ can prior to deformation processing. The true strain of the specimen was calculated using the following equation: 
$\eta=2 \ln \frac{d_{o}}{d_{f}} \quad$ where, $\eta=$ true strain, $d_{o}=$ original

This assembly was swaged at $295 \mathrm{~K}$ to a true strain of $\eta=3.7$ (with appropriate adjustment for collapse of the $30 \%$ porosity of the CIP'ed compact), at which point the $\mathrm{Cu}$ was removed by etching in nitric acid, leaving a $1.45 \mathrm{~mm}$ diameter Au-10Ag composite wire. The bare specimen was then wire drawn to a final diameter of $0.57 \mathrm{~mm} \quad(\eta=5.6)$. Metallography specimens were prepared from the material at $\eta=3.7$ and at $\eta=5.6$. Metallographic specimens were examined in an Amray 1845FE field emission SEM.

Gauge lengths for the five tensile specimens of the $\eta=5.6$ material were reduced $10 \%$ in diameter by micro-grinding on a lathe. Tensile specimens were held in miniature pin vice grips and pulled at $295 \mathrm{~K}$ at a strain rate of $0.0042 \mathrm{~mm} / \mathrm{s}$. Ductility was determined by measuring the fracture surface diameter of each tensile specimen in a traveling optical microscope and comparing that value with the initial diameter of the tensile specimen.

Electrical resistivity measurements were performed using the four-point resistance method at $295 \mathrm{~K}$ on $\eta=5.6 \mathrm{Au}-10 \mathrm{Ag}$ DMMC in the as-drawn condition and after annealing in air at $673 \mathrm{~K}$ for $600 \mathrm{~s}, 2000 \mathrm{~s}$, and 10000 s.

\section{Results and Discussion}

The deformation processing produced a microstructure of Ag filaments, roughly cylindrical in shape, in an $\mathrm{Au}$ matrix, as shown in Figures 3 and 4. The classic 'convoluted ribbon shape' of the $\mathrm{Nb}$ second phase filaments seen in Figures 1 and 2 is not seen in this AuAg DMMC. The fcc structure of the Ag second phase has multiple slip systems, and the plane straining mode seen in bcc $\mathrm{Nb}$ is absent in fcc Ag. For this reason, the $\mathrm{Ag}$ filaments change during deformation processing from equi-axed powder particles to filaments that are approximately cylindrical in shape. This behavior has been observed previously in fcc-fcc DMMC's, such as the eutectic $\mathrm{Ag}-\mathrm{Cu}$ DMMC of Frommeyer and Wassermann (15) and the Cu-24 wt.\% Ag DMMC of Sakai and Schneider-Muntau (16).

The ultimate tensile strength of the $\mathrm{Au}-10 \mathrm{Ag}$ $\eta=5.6$ wire was $550 \mathrm{MPa}$ (standard deviation $=34$ $\mathrm{MPa}$ ), and the ductility measured as reduction in area of the fracture surface was $16 \%$ (standard deviation $8.2 \%)$. The Vickers microhardness of the Au-10Ag wire was 95.3 VHN (standard deviation $=2.2 \mathrm{VHN}$ ) at $\eta=3.7$ and 131.2 $\mathrm{VHN}$ (standard deviation $=7.2$ $\mathrm{VHN}$ ) at $\eta=5.6$. In most DMMC's, the strength and

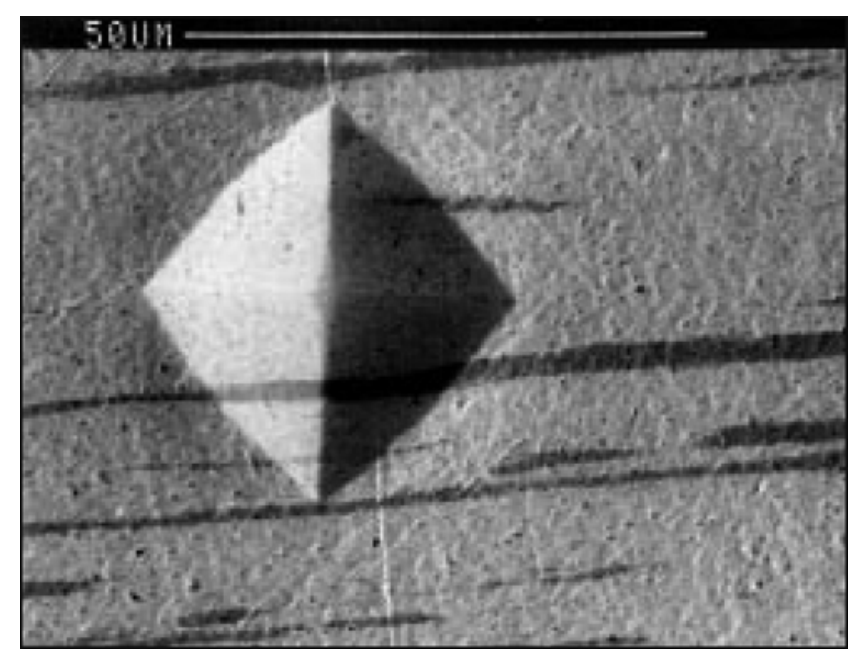

Figure 3 SEM micrograph of a longitudinal section of the $A u^{-}$ Ag composite wire $(\eta=3.7)$. The darker bands are silver filaments in the (lighter) gold matrix in this back-scattered electron image. The indentation in the surface results from a Vickers microhardness test.

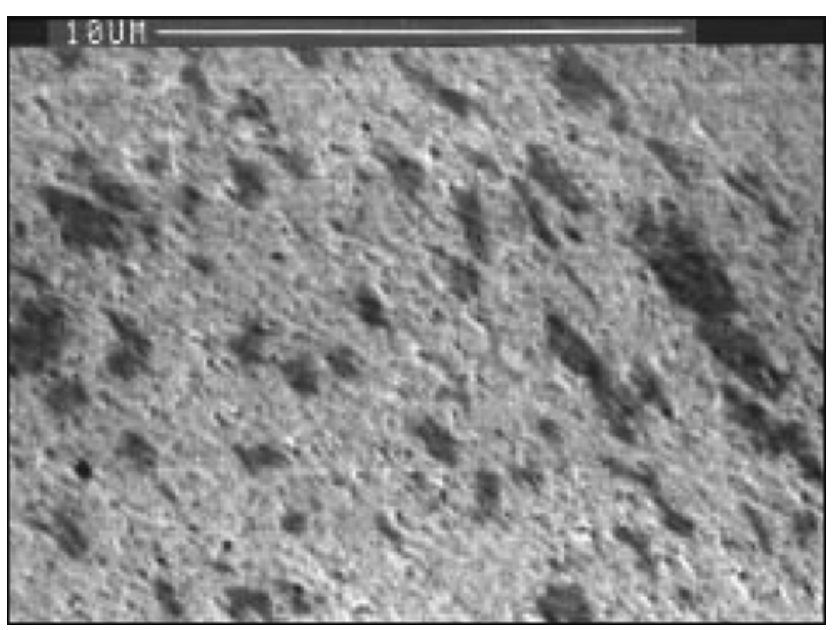

Figure 4 Micrograph of a transverse section of the $A u-A g$ composite wire $(\eta=5.6)$. The darker regions are silver filaments in the (lighter) gold matrix in this backscattered electron image.

hardness increase as the mean true spacing between filaments decreases. Using the stereology methods of Underwood (17), mean center-to-center spacing between the $\mathrm{Ag}$ filaments was measured from transverse section micrographs using the relation:

$\sigma=\frac{1}{N_{L}}$

where $\mathrm{N}_{\mathrm{L}}=$ number of particles intercepted per unit length of circular test line and $\sigma=$ mean center-tocenter spacing. Mean free path $(\lambda)$ between the 
filaments (sometimes called the mean edge-to-edge spacing) is given by the relation:

$\lambda=\frac{1-P_{P}}{N_{L}}$

where $P_{P}$ is the volume fraction of Ag filaments. The average filament thickness $(t)$ of the Ag fibres was measured from transverse section micrographs using the following equation:

$t=\frac{\left(1-P_{M}\right)}{N_{L}}$

where $P_{M}$ is the volume fraction of the matrix. In this Au-10Ag DMMC, the values for phase size and spacing are shown in Table 1.

The $590 \mathrm{~nm} \mathrm{Ag}$ filament thickness in the $\eta=5.6$ Au-10Ag DMMC is much larger than the 10 to $20 \mathrm{~nm}$ filament thicknesses typically seen in DMMC's that have been deformed to higher true strains $(1-4,15)$, suggesting that the strength and hardness of this $\eta=5.6$ Au-10Ag DMMC are probably well below the maximum values attainable in an Au-Ag DMMC. Of the DMMC's previously studied, the system most similar to the $\mathrm{Au}-10 \mathrm{Ag}$ DMMC is the eutectic $\mathrm{Ag}-\mathrm{Cu}$ DMMC of Frommeyer and Wassermann, which had ultimate tensile strength of $1450 \mathrm{MPa}$ at $\eta=9.2$. The considerable ductility of the $\eta=5.6 \mathrm{Au}-10 \mathrm{Ag}$ DMMC also suggests that further deformation processing would be possible. The ultimate tensile strength of the Au-Ag DMMC is about four times greater than the strength of pure annealed gold (18). The microstructures of the Au-Ag DMMC of this study and the $\mathrm{Ag}-\mathrm{Cu}$ DMMC of Frommeyer and Wassermann (15) are essentially identical in shape; however, the $\mathrm{Ag}-\mathrm{Cu}$ DMMC was deformation processed to a higher true strain $(\eta=9.2)$ and has much smaller filament thickness and spacing.

The electrical resistivity of the $\eta=5.6 \mathrm{Au}-10 \mathrm{Ag}$ DMMC was $2.556 \mathrm{mOhm}-\mathrm{cm}$ at $295 \mathrm{~K}$, which is
$8.8 \%$ higher than the resistivity of pure gold $(2.35$ $\mathrm{mOhm}-\mathrm{cm}$ ) (19). Since the composite consists of pure silver filaments in a pure gold matrix with the filaments oriented parallel to the wire axis, the second phase presents a relatively small scattering cross section to current. By comparison, an annealed gold-silver solid solution of this composition was found by other investigators (18) to have a resistivity of $5.13 \mathrm{mOhm}$ $\mathrm{cm}$ and strength of $150 \mathrm{MPa}$.

The microstructure of the Au-10Ag DMMC is metastable. Given sufficient time at elevated temperature, the DMMC will diffuse to form the equilibrium solid solution microstructure. In an effort to characterize this process, pieces of the $\eta=5.6 \mathrm{Au}$ 10Ag DMMC were annealed in air at $673 \mathrm{~K}$ for various time intervals, and the electrical resistivity of these specimens was compared to the resistivities of unannealed $\eta=5.6$ Au-10Ag DMMC and a solid

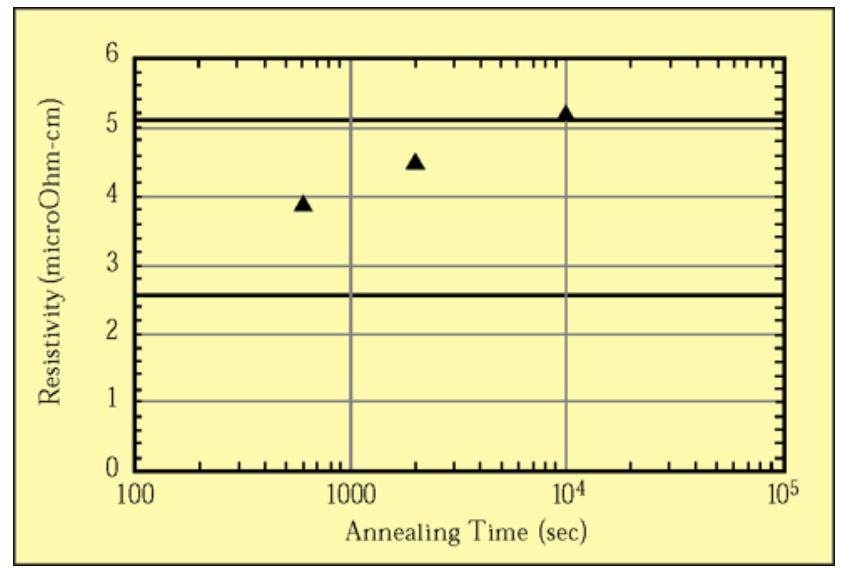

Figure 5 Electrical resistivity versus annealing time in air at $673 \mathrm{~K}$ for $\eta=5.6 \mathrm{Au}-10 \mathrm{Ag}$ DMMC. The lower horizontal line indicates the electrical resistivity of the as-drawn wire with no annealing. The upper horizontal line indicates the electrical resistivity of a $A u-A g$ solid solution of this composition (18).

Table 1 Phase size and spacing for $A u-10 \mathrm{Ag}$ DMMC deformed to $\eta=3.7$ and $\eta=5.6$

$\begin{array}{cc}\text { True Strain }(\eta) & \begin{array}{c}\text { Mean center-to-center } \\ \text { spacing between } \mathbf{A g} \\ \text { filaments }(\sigma) \text { in } \mu \mathrm{m}\end{array} \\ 0 & \mathrm{NA}^{*} \\ 3.7 & 8.1 \\ 5.6 & 6.0\end{array}$

Mean free path between
particles $(\lambda)$ in $\mu \mathrm{m}$
$\mathrm{NA}^{*}$
7.3
5.3

\section{Average filament thickness $(t)$ in $\mu \mathrm{m}$}

* NA, not applicable; the specimen was not fully dense in the as-CIP'd condition.

** Supplier's indicated Ag particle size. Some agglomeration of $\mathrm{Ag}$ particles may have occurred in powder processing of the Ag used in this study. 
solution of this same composition, as shown in Figure 5. Even a 10 minute anneal at $673 \mathrm{~K}$ increases resistivity by more than $50 \%$, presumably due to interdiffusion of the two metals. This behavior is consistent with Fick's Law diffusion calculations; the diffusion coefficients for interdiffusion of $\mathrm{Au}$ and $\mathrm{Ag}$ are relatively high. Producing a gold DMMC with superior high temperature stability would require use of a second phase metal with a diffusion coefficient in Au smaller than in Ag. Several ductile metals suitable for deformation processing have diffusion coefficients in Au that are one to two orders of magnitude smaller than in $\mathrm{Ag}$.

\section{Potential for Further Development}

The significance of this initial attempt at gold matrix DMMC production lies not so much with the properties of the $\eta=5.6 \mathrm{Au}-10 \mathrm{Ag}$ DMMC per se as in the potential it heralds for substantially greater property improvements by refinements in the processing. Although the ultimate tensile strength of $550 \mathrm{MPa}$ at $\eta=5.6$ for the Au-10Ag DMMC is much higher than the strength of pure annealed gold, it is lower than the ultimate tensile strength of several precipitationhardened gold alloys (eg Au-1 wt \% Ti with $\sigma_{\mathrm{UTS}}=1000$ $\mathrm{MPa}$ ) (20). It remains for future studies to determine whether deformation beyond $\eta=5.6$ would further strengthen an $\mathrm{Au}-10 \mathrm{Ag}$ DMMC and whether the $10 \%$ Ag volume is optimal. The authors are preparing to deformation process several larger $\mathrm{Au}-\mathrm{Ag}$ specimens to higher $\eta$ values and to measure their ductility, weldability, and electrical resistivity to explore these potential approaches to achieve higher strength. Additional studies of Au matrix DMMC's with a second phase metal other than $\mathrm{Ag}$ are also underway, and the authors hope to present these results in a second Gold Bulletin article when these studies are completed.

\section{ACKNOWLEDGEMENTS}

This research was supported by NASA's Iowa Space Grant Consortium and by Kulicke \& Soffa Industries, Inc., Willow Grove, PA. The authors acknowledge their valuable discussions with $\mathrm{T}$ Ellis of Kulicke \& Soffa
Industries and the work of L Jones, L Lincoln, P Wheelock, and E Zoellner of the Ames Laboratory Materials Preparation Center for preparing and analyzing the materials used in this study. This work was performed at Ames Laboratory, operated for the US Department of Energy by Iowa State University under contract no. W-7405-ENG-82.

\section{REFERENCES}

1 J. Bevk, J.P. Harbison and J.L. Bell, J. Appl. Phys, 1978, 49 (12), 6031 - 6038

2 J.D. Verhoeven, FA. Schmidt, E.D. Gibson and W.A. Spitzig, J. Metals, 1986, 38 (9), $20-24$.

3 J.D. Verhoeven, A. Spitzig, L.L. Jones, H.L. Downing, C.L. Trybus, E.D. Gibson, L.S. Chumbley, L.G. Fritzmeier and G.D. Schnittgrund, J. Mat. Eng., 1990, 12 (2), $127-139$

4 W. Spitzig. and P.D. Krotz, Acta Metallurgica, 1988, 36 (7), 1709 - 1715

5 J.D. Verhoeven, WA. Spitzig, FA. Schmidt and C.L. Trybus, Mat. Manuf. Processes, 1989, 4 (2), 197 - 209

6 J.D. Verhoeven, WA. Spitzig, F.A. Schmidt, P.D. Krotz and E.D. Gibson, J. Mat. Sci. 1989, 24, $1015-1020$

7 P.D. Funkenbusch and T.H. Courtney, Acta Metallurgica, 1985, 33 (5) . 913-922

8 L.S. Chumbley, H. Downing, W.A. Spitzig and J.D. Verhoeven, Mat. Sci. Eng., 1989, A117, 59 - 65

9 C.L. Trybus, L.S. Chumbley, W.A. Spitzig and J.D. Verhoeven, Ultramicroscopy, 1989 , $30,315-320$

10 P.D. Funkenbusch and T.H. Courtney, Scripta Metallurgica, 1989, 23, 1719-1724

11 W.A. Spitzig, J.D. Verhoeven, C.L. Trybus and L.S. Chumbley, Scripta Metallurgica et Materialia, 1990, 24, 1171-1174

12 J.A. Jensen, A.M. Russell, T.W. Ellis and L.S. Chumbley, in Aluminum and Magnesium for Automotive Applications', ed. J.D. Bryant and D.R. White, TMS Publications, 420 Commonwealth Dr., Warrendale, PA, 1995

13 J.D. Verhoeven, T.W. Ellis, A.M. Russell and L.L. Jones, U.S. Patent 5,200,004, 1993

14 A.M. Russell, L.S. Chumbley, T.W. Ellis, F.C. Laabs, B. Norris and G.E. Donizetti, J. Mat Sci., 1995, 30, 4249-4262

15 G. Frommeyer and G. Wassermann, Acta Metallurgica, 1975, 23, 1353-1360

16 Y. Sakai and H.J. Schneider-Muntau, Acta Materialia, 1997, 45, 1017-1023.

17 E.E. Underwood, 'Quantitative Stereology', Addison-Wesley, Reading, MA, USA 1970, pp. 80-93

18 E.M. Wise, 'Gold: Recovery, Properties, and Applications', D. Van Nostrand Co., Princeton, NJ, USA (1964) 88-104

19 H.E. Boyer and T.L. Gall, ASM Metals Handbook', American Society for Materials, Materials Park, OH, USA, 1985, 1.45

20 G. Humpston and D.M. Jacobson, Gold Bull. 1992, 25, 132-145 